\title{
Role of OCTI in hepatocellular carcinoma
}

This article was published in the following Dove Press journal: OncoTargets and Therapy

\author{
Jingguo $\mathrm{Li}^{\prime}$ \\ Zhengyi Yang ${ }^{2}$ \\ Biguang Tuo'
}

'Department of Gastroenterology, Affiliated Hospital, Zunyi Medical University, Zunyi, People's Republic of China; ${ }^{2}$ Department of Gastroenterology, Bijie First People's Hospital, Bijie, Guizhou Province, People's Republic of China
Correspondence: Biguang Tuo Department of Gastroenterology, Affiliated Hospital, Zunyi Medical University, I49 Dalian Road, Zunyi 563003, People's Republic of China $\mathrm{Tel} / \mathrm{Fax}+8685128609205$

Email tuobiguang@aliyun.com

\begin{abstract}
Hepatocellular carcinoma ( $\mathrm{HCC}$ ) is one of the most commonly diagnosed cancers causing death worldwide. It is difficult to detect at an early stage and most patients with advanced HCC rarely achieve satisfying therapeutic results. Accordingly, researchers have been trying to find new biomarkers for diagnosis and new methods of treatment. OCT1, a member of solute carrier super family, is highly expressed in normal liver tissues, and predominantly transports endogenous and exogenous substances, such as metabolites, drugs and toxins to hepatocytes. Studies have demonstrated that the expression of OCT1 is related to the progression and survival of HCC patients. Furthermore, sorafenib, which is regarded as the only effective molecular targeting drug for advanced HCC, is affected by OCT1 variants. In the current review, we summarized the reports about OCT1 and HCC in order to present a comprehensive overview of the relationship between OCT1 and HCC.
\end{abstract}

Keywords: hepatocellular carcinoma, organic cation transporters, solute carrier transporter family, sorafenib

\section{Introduction}

Hepatocellular carcinoma (HCC) is the sixth most commonly diagnosed cancer and the fourth leading cause of cancer-related mortality worldwide, with about 841,000 new cases and 782,000 deaths annually. ${ }^{1} \mathrm{HCC}$ might be cured by surgical resection, liver transplantation or ablation at the early stage, and 5-year survival can be higher than $50 \%$. Patients with a small single tumor and very good preserved liver function are optimal candidates for surgical resection. Liver transplantation is most beneficial for patients who are not good candidates for resection. ${ }^{2}$ However, most patients are already at advanced stage when HCC is diagnosed. They have no opportunity to accept surgical treatment, and chemotherapy has obviously serious side effects. Therefore, new biomarkers for recognizing $\mathrm{HCC}$ at an early stage and novel treatments for advanced HCC are urgently needed.

The SLC22 transporter family comprises more than two dozen members, which are expressed in epithelial tissues of the kidney, liver, and other organs, and play a critical role in translocating small molecular endogenous metabolites, drugs, and toxins between tissues and interfacing body fluids. ${ }^{3-6}$ Due to the significance in the field of various molecular metabolisms, plenty of attention has been focused on the SLC22 family. SLC22 family is divided into six subfamilies on the basis of substrates and mechanisms of transport, including OATs, OAT-like, OAT-related, OCTs, OCTNs, and OCT/OCTN-related subfamilies. $^{7}$

OCTs contain three subtypes encoded by SLC22A1-3 genes and are plasma membrane carriers of organic cations, weak base, and some neutral compounds. ${ }^{8}$ 
The three membrane transporter subtypes have amino identities about $50 \%-70 \% \%^{9,10}$ and they facilitate their substrates to move bidirectionally across the plasma membrane as cation exchangers depending on the electrochemical gradient of the substrates. ${ }^{9,11,12}$ Natural substrates and drugs transported by organic cation transporters are shown in Table 1. Even though organic cation transporters, OCT1, OCT2, and OCT3, have partly similar distribution in organs, overlapping substrate, and the same inhibitors, they are mainly expressed in different tissues. ${ }^{10,13}$ OCT1 is mainly expressed in the liver, OCT2 is mainly expressed in the basolateral membrane of renal proximal tubules, and OCT3 is highly expressed in skeletal muscle. ${ }^{14-16}$ All of them play important roles in absorption, excretion, and distribution of cationic drugs.

In the human body, almost $40 \%$ of drugs are organic cation in a physiological environment, therefore numerous drugs are potential substrates of OCTs. ${ }^{17}$ More and more studies have demonstrated that OCTs, to a small or large extent, play a role in cellular uptake of multiple drugs and the development of drug resistance in various diseases, and also influence the progression and survival of cancers and the response to anti-cancer drugs in human malignant tumors. Especially, much attention has been paid to the role of OCT1 in HCC.

This review therefore aimed to show the expression of OCT1 in normal liver tissue and HCC tissue, and elucidate certain defined relationships between OCT1 and HCC, and summarize recent research progress regarding OCT1 and HCC. We believe that a comprehensive overview will contribute to a better understanding of the role of OCT1 in HCC and we aimed to further investigate characteristics of OCT1 in HCC and provide a new therapeutic approach for HCC treatment.

\section{Structure and variant of OCT I}

OCT1 was first cloned from a rat in $1994,{ }^{18}$ and first cloned from a human and described in detail in 1997. ${ }^{19,20}$ The human OCT1 encoded by SLC22A1 gene is located on chromosome 6q25-q27 in a cluster and the gene contains eleven exons and ten introns, with a span of approximately $37.41 \mathrm{~kb}^{21-24}$ The OCT1 protein has 554 amino acids and consists of $12 \alpha$-helical transmembrane domains (TMDs) with $\mathrm{N}$ - and C-termini localized in intracellular position. The site of OCT1 protein in intracellular loop between TMD6 and TMD7 domains is phosphorylated posttranslationally. ${ }^{25,26}$ Additionally, residues of certain amino acids, including cysteine, glycine, and proline, are rather conserved in overall OCTs cloned hitherto, indicating that these residues play a pivotal role in the establishment of the secondary structure of these proteins. ${ }^{27}$ When cation combines with OCT1, the conformation of transporter will be changed and finally OCT1 mediates the transposition across plasma membrane. ${ }^{28}$

Notably, there are many single nucleotide polymorphisms (SNPs) in SLC22A1 gene, which results in the presence of numerous SLC22A1 variants. ${ }^{28,29}$ It has been confirmed that the existence of genetic variants in genes encoding proteins relating to the processes of drug detoxification is responsible for drug reaction, and sometimes contributes to serious consequences in regard to drug toxicity and therapeutic effect. ${ }^{30} \mathrm{~A}$ broad range of drugs applied in clinical treatment are organic cations, therefore the genetic variant of SLC22A1 gene has important clinical significance for human pharmacology. For example, a variant of SLC22A1 gene inserted by an $8 \mathrm{bp}$ in intron 7 between exons 7 and 8 brings about a truncated protein, which probably predisposes toward universality of adverse side effects in metformintreated type 2 diabetes patients. ${ }^{31}$ SLC22A1 gene has more than 1,000 site-mutations in the open reading frame, in the

Table I Natural substrates and drugs transported by organic cation transporters (OCTs)

\begin{tabular}{|c|c|c|}
\hline OCTs & Natural substrates & Drugs \\
\hline OCTI & $\begin{array}{l}\text { TEA, MPP, ASP, acetylcholine, choline, corticosterone, epinephrine, } \\
\text { histamine, guanidine, salsolinol serotonin, thiamine, progesterone, } \\
\text { prostaglandin } E_{2} / F_{2 \cdot}^{9,22,96-101}\end{array}$ & $\begin{array}{l}\text { Acyclovir, atenolol, debrisoquine, furamidine, ganciclovir, } \\
\text { lamivudine, lamotrigine, metformin, oxaliplatin, pentamidine, } \\
\text { picoplatin, tropisetron, zalcitabine. }\end{array}$ \\
\hline OCT2 & $\begin{array}{l}\text { TEA, MPP, ASP, N-methylnicotinamide, aminoguanidine, } \\
\text { acetylcholine, dopamine, epinephrine, norepinephrine, serotonin, } \\
\text { histamine, cyclo (His-Pro), salsolinol, agmatinepolyamine, } \\
\text { putrescine, choline. }{ }^{22,100,101}\end{array}$ & $\begin{array}{l}\text { Amantadine, amiloride, atenolol, cimetidine, cisplatin, famotidine, } \\
\text { ifosfamide, lamivudine, memantine, metformin, oxaliplatin, } \\
\text { picoplatin. }{ }^{102-103,106}\end{array}$ \\
\hline OCT3 & $\begin{array}{l}\text { epinephrine, norepinephrine, histamine, agmatine, cyclo (His-Pro), } \\
\text { salsolinol. }{ }^{101} \text {, }\end{array}$ & $\begin{array}{l}\text { Cisplatin, etilefrine, lamivudine, lidocaine, metformin, oxaliplatin, } \\
\text { pramipexole, quinidine. }\end{array}$ \\
\hline
\end{tabular}

Abbreviations: TEA, tetraethylammonium; MPP, I-methyl-4-phenylpyridinium; ASP, 4-[4-(dimthylamino)-styryl]-Nmethylpyridinium. 
promoter sequence, even in certain introns described in previous reports. However, we still have no complete understanding about the biological implication of numerous SNPs in the untranslated regions. ${ }^{32-34}$ Except for the transcript variant hOCT1G/L554, most of OCT1 transcript variants will be translated into truncated proteins on account of the "skip" of certain exons and retention of several introns in variant mRNAs. $^{23,28}$ This is the reason why many previous reports show that OCT1 variant tends to be less functional or non-functional. ${ }^{17,32,35-37}$ Regarding some less functional or non-functional OCT1 variants, the alterations of evolutionarily conserved glycine residues were observed, and the result indicates that these residues may play a key role in the function of OCT1. ${ }^{35,36}$ Thus, amino acid variant has peculiar biological value for providing information about whether these residues mediate activity of protein and specificity of substrate. $^{25}$

Some studies also demonstrated that several nonsynonymous mutations exist on the SLC22A1 gene in each subject from different racial groups, such as L160F, P341L, and M408V. In addition, these variants still maintained transport ability own relatively high frequency in SLC22A1 gene. ${ }^{38}$ However, not overall SLC22A1 gene mutations exhibit reduced function of transporters. For instance, patients suffering from chronic myeloid leukemia with the wild-type L160F variant have a worse response to imatinib than those with the mutation. ${ }^{39}$

\section{Function of OCTI}

OCT1, the poly-specific amphiphilic solute facilitator of transmembrane protein, transports organic cations electrogenically independent of $\mathrm{Na}^{+}$and $\mathrm{H}^{+}$gradients. ${ }^{19,40}$ Since OCT1 is mainly expressed in the liver, OCT1 predominates not only in the delivery of many endogenous substrates and cationic drugs into hepatocytes from sinusoids, but also in the release of organic cations from hepatocytes to sinusoids. ${ }^{17,22,41}$ In hepatocytes, OCT1 mediates the detoxification of various endogenous or xenobiotic substrates in the first step. ${ }^{25,42}$

OCT1 is also involved in relevant transport of substances in other organs, such as the absorption and secretion of organic cations in the small intestine, ${ }^{9,41}$ reabsorption of ultra-filtrated cations in the kidney and absorption of certain drugs in lungs. ${ }^{41,43}$ Additionally, OCT1 promotes organic cations to traverse the blood-brain barrier in the brain and motivates the uptake of endogenous substrates and antiviral drugs in human immune cells. ${ }^{44,45}$

\section{Expression and regulation of OCT I in the liver}

As described previously, OCT1 protein is expressed mainly in the liver, located in the basolateral sinusoidal membrane of normal hepatocytes and to a lesser degree in cholangiocytes. However, there are big differences in OCT1 protein and mRNA levels in different people. The high variation of OCT1 protein and mRNA levels (83- and 113-, respectively) was shown in 136 of 150 liver samples collected from Caucasian subjects. Similarly, this high variation (23.6- and 15.9-fold, respectively) was also detected in a Korean population. The correlation coefficient value of OCT1 protein and mRNA is just 0.53 , which probably means very low post-transcriptional regulation of SLC22A1 gene expression. ${ }^{17,46}$ The hepatic OCT1 mRNA possesses the highest expression in all human organs, but OCT1 transcripts have a pretty low expression in various other organs, such as the brain, testis, small intestine, spleen, mammary gland, eye, heart, kidney, lung, adipose tissue, skeletal muscles, and immune cells. ${ }^{14,17,45,47-52}$ Similarly, OCT1 protein is also expressed in other tissues in low levels. OCT1 is localized to the lateral and basolateral membranes of enterocytes, ${ }^{53,54}$ the luminal membrane of pulmonary epithelial cells, ${ }^{43,55}$ and the endothelial cells of brain microvessels. ${ }^{44}$

Also, OCT1 expression in various tumor cells has been demonstrated, such as HCC cells, lung cancer cells, and lymphoma cells. ${ }^{56-59}$ Significant down-regulation of OCT1 expression was detected in a variety of liver cancer tissues, such as HCC, cholangiocarcinoma (CCA), and hepatoblastoma, compared with adjacent non-tumor liver tissue. ${ }^{37,60-62}$

OCT1, predominating in hepatic uptake and excretion of cationic drugs and endogenous substances, is highly expressed only in hepatic parenchyma cells. Apparently, it implies that the expression of OCT1 is possibly regulated by certain liver-enriched transactivators. Saborowski et al found that HNF-4 $\alpha$ can activate SLC22A1 gene to encode OCT1 protein via binding to two contiguous DNAresponse elements contained by OCT1 promoter. ${ }^{63}$ Some reports showed that HNF- $4 \alpha$ also regulates the expression of many genes affecting most aspects of healthy hepatic function. ${ }^{64-70}$ These functions refer to regulation of hepatic cell development, differentiation, bile acid synthesis, xenobiotic detoxification, serum protein production, and energy metabolism. ${ }^{71}$ On the other hand, bile acid chenodeoxycholic acid (CDCA) is a typical ligand of farnesoid $\mathrm{X}$ receptor. The activation of HNF- $4 \alpha$ to OCT1 tends to be 
interrupted by CDCA via interference of small heterodimer partner (SHP) (Figure 1A). ${ }^{63}$ Thus, when patients have cholestatic liver disease, OCT1 expression is down-regulated due to the increasing bile acid level which interferes with the promotion of OCT1 transcription by HNF-4 $\alpha$. Further studies demonstrated that upstream stimulating factors (USFs), USF1 and USF2, served as pivotal transcriptional regulators of the SLC22A1 gene via an E-box (CAGTG) which is located in the SLC22A1 core promoter region with abundant transcriptional factors, increasing the HNF-4 $\alpha$-mediated transactivation of SLC22A1 gene in another way. ${ }^{72}$ In a hepatocyte-derived cell lines model, the HNF-4 $\alpha$-mediated transactivation of SLC22A1 gene was repressed by ligand-mediated activation of PXR via competing for SRC-1 with HNF-4 $\alpha$ and USFs, for example, rifampicin, a ligand of $\mathrm{PXR}$, can activate PXR to down-regulate SLC22A1 gene indirectly (Figure 1B). ${ }^{73}$ This competition is called squelching. ${ }^{74,75}$ In addition, Rulcova et al showed that glucocorticoids could transactivate SLC22A1 gene via up-regulating HNF-4 $\alpha$ (Figure 1C). ${ }^{76}$ Moreover, there are also additional transcription factors, such as CCAAT/C/EBP $-\alpha,-\beta$, and $-3 \gamma$, which generate a special effect on the transcription regulation of hepatic drug transporters. ${ }^{77,78}$

Ciarimboli et al established two different OCT1 expression systems, hOCT1-transfected Chinese hamster ovary cell line (CHO-K1) and human embryonic kidney cortex cells (HEK293-cells), to investigate the regulation mechanism of OCT1 protein function. ${ }^{42}$ It has been shown that there are diverse intracellular signaling pathways which, together, regulate the function of OCT1. For example, OCT1 is negatively regulated by activation of PKA and endogenously positively regulated by the $\mathrm{Ca}^{2+} / \mathrm{CaM}$ complex, the $\mathrm{Ca}^{2+} / \mathrm{CaM}$-dependent CaMK II by PKA, and p56 ${ }^{\text {lck }}$ tyrosine kinase. Additionally, the result demonstrated that OCT1 defers in the same regulatory signaling pathway in different expression systems and also showed that the activation or inhibition of specific regulatory patterns and different expression systems collectively influences substrate affinities to a greater or lesser degree. ${ }^{42,79}$

\section{OCTI and development and progression of HCC}

There are big discrepancies of OCT1 expression between hepatic tumor cell lines and healthy human hepatocytes. Heise et al first described the expression profiles of OCTs in a bigger series of human $\mathrm{HCC}$, and the analysis of experimental data indicated that $\mathrm{HCC}$ patients with low expression of OCT1 usually progress to further advanced HCC stage and have worse survival than those with relatively high expression of OCT1. ${ }^{62}$ Schaeffeler et al demonstrated that OCT1 expression in HCC is significantly inversely correlated with expression of the tumor proliferation marker MIB1/Ki-67, ${ }^{56}$ indicating that OCT1 inhibits tumor proliferation via certain pathways. Previous studies also showed that MIB1/Ki-67 expression was decreased in diethylnitrosamine-treated $\mathrm{JNK}^{-/-}$knockout mice $^{80}$ and that the high activation of JNK1 in HCC tissues is related to the reduction of OCT1 mRNA expression and worse prognosis. ${ }^{81}$ In addition, the study from Lautem et al also found that the expression of OCT1 was down-regulated in patients with cholangiocellular carcinoma, which was closely related to larger tumor sizes or advanced tumor stage and a poorer overall patient survival. $^{82}$

The fundamental mechanisms accounting for the reduced OCT1 expression in HCC tissues are still not understood completely. The study from Schaeffeler et al showed that DNA methylation of OCT1 is associated with down-regulation of OCT1 in HCC. ${ }^{56}$ Several studies discussed the reasons of abnormal DNA methylation level in HCC. Lambert et al demonstrated that the methylation state in defined genes in HCC is affected by alcohol intake or viral infection, therefore inducing hepatocarcinogenesis. ${ }^{83}$ Even though the understanding of the reduced expression of OCT1 in hepatic malignant cells is still not enough and the specific causes of aberrant DNA methylation may need to be elucidated further, undoubtedly, we can regard DNA methylation index of OCT1 as a novel molecular marker for diagnosing $\mathrm{HCC}$ at the early stage, and it may provide a new therapeutic method, such as pretreatment of demethylation, for patients with HCC. ${ }^{56}$

\section{OCTI and HCC treatment}

Traditional chemotherapeutic drugs for HCC fail to obtain a relevant survival benefit because of marked chemoresistance. ${ }^{84,85}$ Sorafenib is one of the most effective drugs to conquer chemo-resistance in primary HCC. ${ }^{37}$ Although sorafenib is a pretty effective antitumor drug in $\mathrm{HCC}$ treatment, it results in different effects in clinical therapy. Honestly, sorafenib treatment is far below optimal expectation by reason of a pronounced refractoriness that liver tumors possess originally to sorafenib. ${ }^{86} \mathrm{Up}$ to now, many studies have been conducted to investigate the fundamental mechanisms of the response to sorafenib and 


\section{A}

Chenodeoxycholic acid (CDCA)
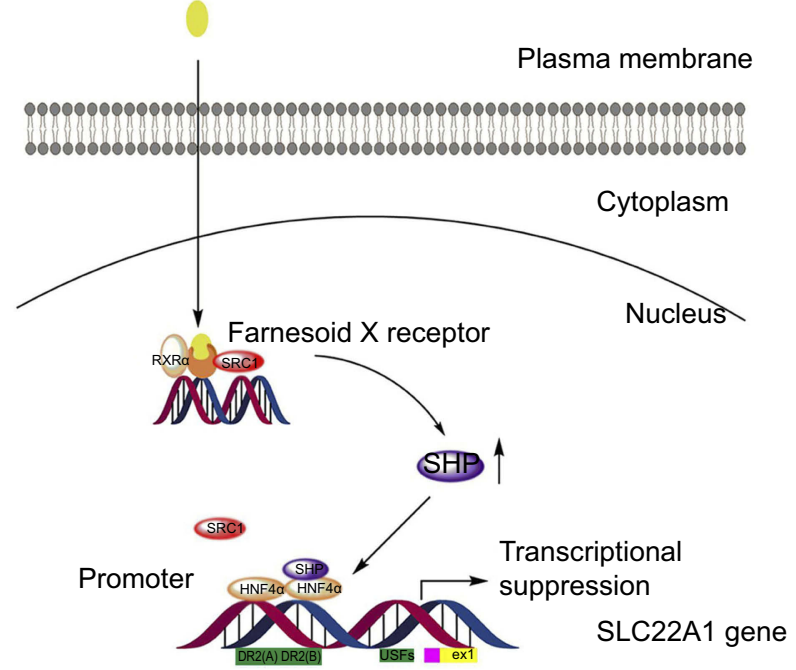

C

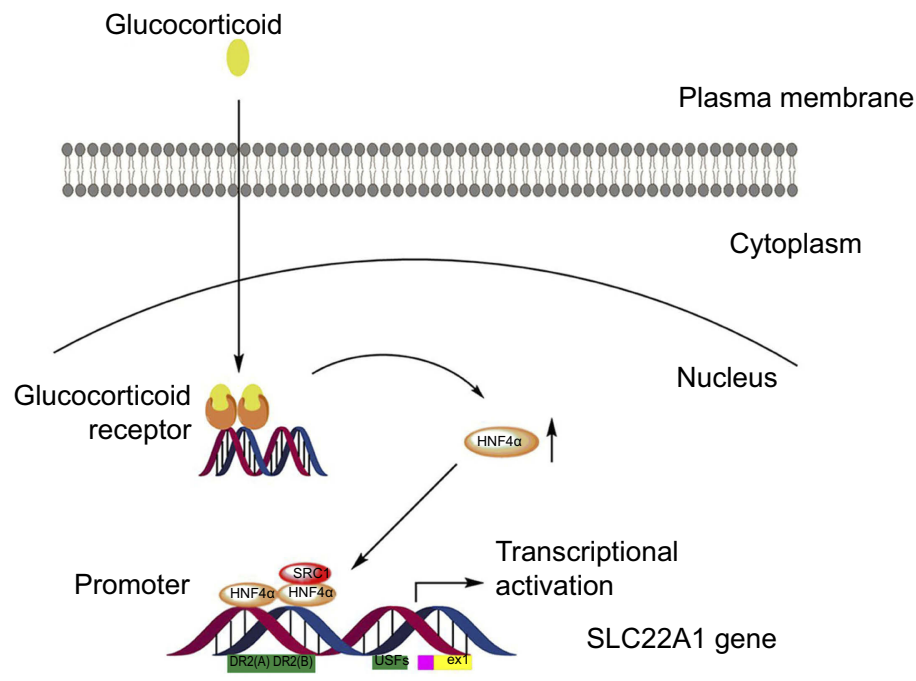

B

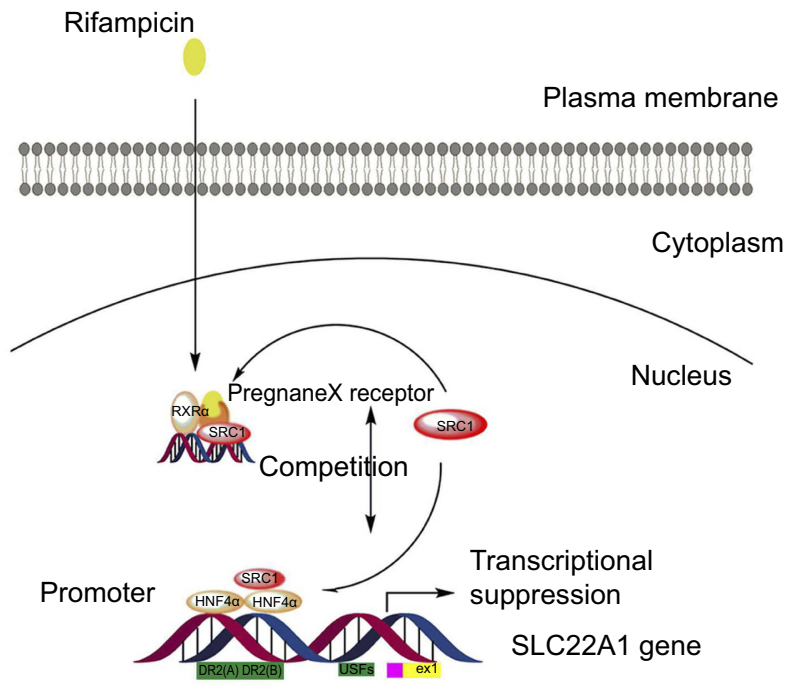

Figure I Schemes of pathways/processes affecting OCTI expression.

Notes: (A) The SLC22AI gene tends to be suppressed by CDCA via interference of small heterodimer partner (SHP), which can co-repress HNF-4 $\alpha$ transactivation. (B) PXR is activated by rifampicin to compete for SRC-I with HNF-4 $\alpha$, and thus represses the HNF- $4 \alpha-$ mediated transactivation of SLC22AI gene. (C) The HNF-4 $\alpha$ mediated transactivation of SLC22AI gene is activated by glucocorticoids binding glucocorticoids receptor via up-regulating HNF-4 $\alpha$.

Abbreviation: CDCA, chenodeoxycholic acid.

trials have been carried out to surmount the obtainment of this drug resistance.

The heterogeneity of antitumoral efficacies of sarafenib in different patients, and the drug-related adverse side effects of sorafenib treatment make it essential to recognize biomarkers either in tumor tissue or peripheral blood to predict therapeutic outcomes of patients in individual treatment schemes. ${ }^{87}$ Phorbolmyristate acetate-induced phosphorylation of ERK has been considered as a blood biomarker ${ }^{88}$ and in addition, the level of pERK expression was identified as an ideal intratumoral marker of drug response. ${ }^{89}$ Not only the presence of the molecular targets of sorafenib in hepatic tumors, but also the expression of various drug transporters displays a putative indicator of response to treatment. The specific mechanism of action of sorafenib is determined by access to intracellular targets, which may be affected by alteration of the expression and activity of transporters responsible for its uptake. ${ }^{37,87}$ OCT1 plays a key role in the uptake of sorafenib in hepatic cells, which has encouraged numerous teams to 
study the availability of OCT1 expression as a useful biomarker for response to sorafenib therapy for HCC. $^{25,37,90}$ Grimm et al reported that intratumoral OCT1 mRNA expression probably played a promising role as a prognostic biomarker for HCC patients receiving sorafenib treatment. ${ }^{90}$

Substrates mediated by OCT1 are endogenous and exogenous organic cations, involving drugs like metformin, anthracyclines, platinum derivatives, and tyrosine kinase inhibitors. ${ }^{22,38,91,92}$ Generally, the drug-relevant transporter determines the response to the drug via affecting uptake of the drug in hepatocytes, for example, metformin is influenced by alterations in OCT1 expression and by the presence of impaired functional variants. ${ }^{35}$ And there is a similar relationship between OCT1 genic mutations and a lower response to imatinib in patients with chronic myeloid leukemia. ${ }^{93}$ Does this relationship still exist between OCT1 and sorafenib? Herraez et al reported that two novel identified variants of OCT1, R61S fs*10 and C88A fs*16, which encode truncated proteins unable to get to the plasma membrane, were expressed in HCC. Both the presence of less functional variants and down-regulated expression of OCT1 together, probably significantly affected the uptake and response of these tumors to sorafenib. ${ }^{37} \mathrm{~A}$ further experiment from Geier et al found that there was no difference in sorafenib response in HCC tissues with and without OCT1 expression, but when considering OCT1 expression level at the plasma membrane of HCC cells, a pronounced better survival was presented in patients with high expression level at the plasma membrane. ${ }^{87}$ They thus concluded that the expression of OCT1 at the plasma membrane is more significantly associated with a beneficial response in HCC patients treated with sorafenib rather than overall OCT1 expression. Thus, based on the views of Herraezetal and Geieretal, we easily see that variants and expression of OCT1 are possibly not the root reasons contributing to reduced sensitivity to sorafenib, and the effective expression of OCT1 at the plasma membrane may determine the response to sorafenib in patients with HCC. Considering that a large proportion of synthesized OCT1 mRNA is constituted by non-functional aberrant variants, Geieretal investigated the association between OCT1 and HCC at the level of proteins in order to reflect OCT1 function better. ${ }^{87}$ And another surprising finding of this research was that expression of OCT1 protein at the plasma membrane did not correlate with tumor stage and previous treatment with transcatheter arterial chemoembolization or radiotherapy. Interestingly, Ruba et al recently showed that epigenetic factors and highly aberrant splicing, including miRNA-mediated mRNA decay and hypermethylation, can partly account for the low expression of OCT1 in HCC, and the down-regulated OCT1 triggers impaired sorafenib uptake and cytotoxic events. ${ }^{94}$ Also, Lozano et al found a similar result in CCA, which showed that promoter hypermethylation, aberrant splicing, and miRNA-mediated degradation resulted in reduction of OCT1 mRNA and sorafenib uptake/response in CCA. ${ }^{95}$ These discoveries also shed new light on the relationship among OCT1, sorafenib, and HCC. Based on these reports, OCT1 truly plays a critical role in response to sorafenib in HCC patients and is deeply involved in the development of sorafenib chemo-resistance.

\section{Conclusion}

In this review, we focused on research progress of OCT1 and the relationship between OCT1 and HCC in the last 2 decades. A number of achievements have been made in the field of regulatory mechanisms of OCT1 in healthy liver. The specific roles of OCT1 in the occurrence and progression of HCC are still elusive, and the precise molecular mechanisms of down-regulated OCT1 expression in HCC still need further investigation. However, we can confirm that OCT1-related functions are profound and novel targets for HCC research.

From existing studies of OCT1, it has been shown that OCT1 variant is an essential part of OCT1 subset, and we predict that perhaps a variant of OCT1 plays a critical role in many fields, including physiological and pathological conditions. There is still a great number of functions and presence of OCT1 variants to be found in the future, and further studies are urgently needed to comprehensively describe more mechanisms, epigenetic factors, transcriptional, and post-transcriptional factors regulating OCT1 expression and function in HCC.

OCT1 is involved in the formation of sorafenib resistance as well as in the uptake of sorafenib in HCC cells. Further studies are necessary to understand and solve this contradiction between OCT1 and sorafenib. On one hand, maybe we could look for the breakthrough at the level of amino acid residues of OCT1 variants, since the changes in these residues play a key role in the appearance of dysfunctional OCT1 variants, which dramatically affected the response of HCC patients to sorafenib. On the other hand, whether OCT1 has any connection with other various signaling pathways of developing sorafenib resistance, is also worth being considered. 


\section{Acknowledgments}

This work was supported by the National Natural Science Foundation of China (81572438) (B. Tuo), and the Foundation of Academician Work Station for Digestive Diseases, Bijie First People's Hospital, Guizhou Province, People's Republic of China.

\section{Author contributions}

All authors contributed to data analysis, drafting or revising the article, gave final approval of the version to be published, and agree to be accountable for all aspects of the work.

\section{Disclosure}

The authors report no conflicts of interest in this work.

\section{References}

1. Bray F, Ferlay J, Soerjomataram I, Siegel RL, Torre LA, Jemal A. Global cancer statistics 2018: GLOBOCAN estimates of incidence and mortality worldwide for 36 cancers in 185 countries. $C A$ Cancer J Clin. 2018;68(6):394-424. doi:10.3322/caac.21492

2. Forner A, Llovet JM, Bruix J. Hepatocellular carcinoma. Lancet 2012;379(9822):1245-1255. doi:10.1016/S0140-6736(11)61347-0

3. Rizwan AN, Burckhardt G. Organic anion transporters of the SLC22 family: biopharmaceutical, physiological, and pathological roles. Pharm Res. 2007;24(3):450-470. doi:10.1007/s11095-0069181-4

4. Pelis RM, Wright SH. SLC22, SLC44, and SLC47 transportersorganic anion and cation transporters: molecular and cellular properties. Curr Top Membr. 2014;73:233-261. doi:10.1016/B978-012-800223-0.00006-2

5. Nigam SK. What do drug transporters really do? Nat Rev Drug Discov. 2015;14(1):29-44. doi:10.1038/nrd4461

6. Giacomini KM, Shiew-Mei H, Tweedie DJ, et al. Membrane transporters in drug development. Nat Rev Drug Discov. 2010;9(3):215. doi: $10.1038 / \mathrm{nrd} 3028$

7. Zhu C, Nigam KB, Date RC, et al. Evolutionary analysis and classification of OATs, OCTs, OCTNs, and other SLC22 transporters: structure-function implications and analysis of sequence motifs. PLoS One. 2015;10(11):e0140569. doi:10.1371/journal. pone. 0140569

8. Koepsell H. In vivo two-photon fluorescence microscopy opens a new area for investigation of the excretion of cationic drugs in the kidney. Kidney Int. 2007;72(4):387-388. doi:10.1038/sj.ki.5002239

9. Koepsell H. Role of organic cation transporters in drug-drug interaction. Expert Opin Drug Metab Toxicol. 2015;11(10):1619-1633. doi:10.1517/17425255.2015.1069274

10. Koepsell H, Schmitt BM, Gorboulev V. Organic cation transporters. Rev Physiol Biochem Pharmacol. 2003;150:36-90.

11. Koepsell H. Substrate recognition and translocation by polyspecific organic cation transporters. Biol Chem. 2011;392(1-2):95-101. doi:10.1515/BC.2011.009

12. Koepsell H, Endou H. The SLC22 drug transporter family. Pflugers Arch. 2004;447(5):666-676. doi:10.1007/s00424-003-1089-9

13. Ciarimboli G. Organic cation transporters. Xenobiotica. 2008;38(78):936-971. doi:10.1080/00498250701882482

14. Nishimura M, Naito S. Tissue-specific mRNA expression profiles of human ATP-binding cassette and solute carrier transporter superfamilies. Drug Metab Pharmacokinet. 2005;20(6):452-477. doi:10.2133/dmpk.20.452
15. Karbach U, Kricke J, Meyer-Wentrup F, et al. Localization of organic cation transporters OCT1 and OCT2 in rat kidney. Am J Physiol Renal Physiol. 2000;279(4):F679-F687. doi:10.1152/ajprenal.2000.279.4.F679

16. Motohashi H, Sakurai Y, Saito H, et al. Gene expression levels and immunolocalization of organic ion transporters in the human kidney. J Am Soc Nephrol. 2002;13(4):866-874.

17. Nies AT, Koepsell H, Winter S, et al. Expression of organic cation transporters OCT1 (SLC22A1) and OCT3 (SLC22A3) is affected by genetic factors and cholestasis in human liver. Hepatology. 2009;50(4):1227-1240. doi:10.1002/hep.23103

18. Grundemann D, Gorboulev V, Gambaryan S, Veyhl M, Koepsell H. Drug excretion mediated by a new prototype of polyspecific transporter. Nature. 1994;372(6506):549-552. doi:10.1038/372549a0

19. Gorboulev V, Ulzheimer JC, Akhoundova A, et al. Cloning and characterization of two human polyspecific organic cation transporters. DNA Cell Biol. 1997;16(7):871-881. doi:10.1089/dna.1997.16.871

20. Zhang L, Dresser MJ, Gray AT, Yost SC, Terashita S, Giacomini KM. Cloning and functional expression of a human liver organic cation transporter. Mol Pharmacol. 1997;51(6):913-921.

21. Koehler MR, Wissinger B, Gorboulev V, Koepsell H, Schmid M. The two human organic cation transporter genes SLC22A1 and SLC22A2 are located on chromosome 6q26. Cytogenet Cell Genet. 1997;79(3-4):198-200. doi:10.1159/000134720

22. Koepsell H, Lips K, Volk C. Polyspecific organic cation transporters: structure, function, physiological roles, and biopharmaceutical implications. Pharm Res. 2007;24(7):1227-1251. doi:10.1007/ s11095-007-9254-z

23. Hayer M, Bonisch H, Bruss M. Molecular cloning, functional characterization and genomic organization of four alternatively spliced isoforms of the human organic cation transporter 1 (hOCT1/SLC22A1). Ann Hum Genet. 1999;63(Pt 6):473-482. doi: $10.1017 / \mathrm{S} 0003480099007770$

24. Grundemann D, Schomig E. Gene structures of the human non-neuronal monoamine transporters EMT and OCT2. Hum Genet. 2000;106 (6):627-635.

25. Lozano E, Herraez E, Briz O, et al. Role of the plasma membrane transporter of organic cations OCT1 and its genetic variants in modern liver pharmacology. Biomed Res Int. 2013;2013:692071. doi: $10.1155 / 2013 / 692071$

26. Wright SH. Role of organic cation transporters in the renal handling of therapeutic agents and xenobiotics. Toxicol Appl Pharmacol. 2005;204(3):309-319.

27. Burckhardt G, Wolff NA. Structure of renal organic anion and cation transporters. Am J Physiol Renal Physiol. 2000;278(6): F853-F866. doi:10.1152/ajprenal.2000.278.6.F853

28. Hyrsova L, Smutny T, Trejtnar F, Pavek P. Expression of organic cationtransporter 1 (OCT1): unique patterns of indirect regulation by nuclear receptors and hepatospecific gene regulation. Drug Metab Rev. 2016;48(2):139-158. doi:10.1080/03602532.2016.1188936

29. Sakata T, Anzai N, Shin HJ, et al. Novel single nucleotide polymorphisms of organic cation transporter 1 (SLC22A1) affecting transport functions. Biochem Biophys Res Commun. 2004;313 (3):789-793. doi:10.1016/j.bbrc.2003.11.175

30. Marin JJ, Briz O, Monte MJ, Blazquez AG, Macias RI. Genetic variants in genes involved in mechanisms of chemoresistance to anticancer drugs. Curr Cancer Drug Targets. 2012;12(4):402-438.

31. Tarasova L, Kalnina I, Geldnere K, et al. Association of genetic variation in the organic cation transporters OCT1, OCT2 and multidrug and toxin extrusion 1 transporter protein genes with the gastrointestinal side effects and lower BMI in metformin-treated type 2 diabetes patients. Pharmacogenet Genomics. 2012;22 (9):659-666. doi:10.1097/FPC.0b013e3283561666

32. Kerb R, Brinkmann U, Chatskaia N, et al. Identification of genetic variations of the human organic cation transporter hOCT1 and their functional consequences. Pharmacogenetics. 2002;12(8):591-595. 
33. Saito S, Iida A, Sekine A, et al. Catalog of 238 variations among six human genes encoding solute carriers (hSLCs) in the Japanese population. J Hum Genet. 2002;47(11):576-584. doi:10.1007/ s100380200088

34. Itoda M, Saito Y, Maekawa K, et al. Seven novel single nucleotide polymorphisms in the human SLC22A1 gene encoding organic cationtransporter 1 (OCT1). Drug Metab Pharmacokinet. 2004;19 (4):308-312. doi:10.2133/dmpk.19.308

35. Shu Y, Sheardown SA, Brown C, et al. Effect of genetic variation in the organic cation transporter 1 (OCT1) on metformin action. $J$ Clin Invest. 2007;117(5):1422-1431. doi:10.1172/JCI30558

36. Shu Y, Leabman MK, Feng B, et al. Evolutionary conservation predicts function of variants of the human organic cation transporter, OCT1. Proc Natl Acad Sci USA. 2003;100(10):5902-5907. doi:10.1073/pnas.0730858100

37. Herraez E, Lozano E, Macias RI, et al. Expression of SLC22A1 variants may affect the response of hepatocellular carcinoma and cholangiocarcinoma to sorafenib. Hepatology. 2013;58(3):10651073. doi: $10.1002 /$ hep. 26425

38. Shikata E, Yamamoto R, Takane H, et al. Human organic cation transporter (OCT1 and OCT2) gene polymorphisms and therapeutic effects of metformin. J Hum Genet. 2007;52(2):117-122. doi:10.1007/s10038-006-0087-0

39. Kim DH, Sriharsha L, Xu W, et al. Clinical relevance of a pharmacogenetic approach using multiple candidate genes to predict response and resistance to imatinib therapy in chronic myeloid leukemia. Clin Cancer Res. 2009;15(14):4750-4758. doi:10.1158/ 1078-0432.CCR-09-0145

40. Koepsell H, Gorboulev V, Arndt P. Molecular pharmacology of organic cation transporters in kidney. J Membr Biol. 1999;167 (2):103-117.

41. Jonker JW, Schinkel AH. Pharmacological and physiological functions of the polyspecific organic cation transporters: OCT1, 2, and 3 (SLC22A1-3). J Pharmacol Exp Ther. 2004;308(1):2-9.

42. Ciarimboli G, Struwe K, Arndt P, et al. Regulation of the human organic cation transporter hOCT1. J Cell Physiol. 2004;201 (3):420-428. doi:10.1002/jcp.20081

43. Ingoglia F, Visigalli R, Rotoli BM, et al. Functional characterization of the organic cation transporters (OCTs) in human airway pulmonary epithelial cells. Biochim Biophys Acta. 2015;1848(7):1563-1572.

44. Lin CJ, Tai Y, Huang MT, et al. Cellular localization of the organic cation transporters, OCT1 and OCT2, in brain microvessel endothelial cells and its implication for MPTP transport across the blood-brain barrier and MPTP-induced dopaminergic toxicity in rodents. $J$ Neurochem. 2010;114(3):717-727. doi:10.1111/ j.1471-4159.2010.06801.x

45. Minuesa G, Purcet S, Erkizia I, et al. Expression and functionality of anti-human immunodeficiency virus and anticancer drug uptake transporters in immune cells. J Pharmacol Exp Ther. 2008;324 (2):558-567.

46. Kim MH, Shin HJ, Lim SJ, et al. Inter-individual variability in OCT1 expression and its relationship with OCT1 genotype in liver samples from a Korean population. Drug Metab Pharmacokinet. 2012;27(5):530-535. doi:10.2133/dmpk.DMPK-11-RG-109

47. Aoki M, Terada T, Kajiwara M, et al. Kidney-specific expression of human organic cation transporter 2 (OCT2/SLC22A2) is regulated by DNA methylation. Am J Physiol Renal Physiol. 2008;295(1): F165-F170. doi:10.1152/ajprenal.90257.2008

48. Zhang T, Xiang CD, Gale D, Carreiro S, Wu EY, Zhang EY. Drug transporter and cytochrome P450 mRNA expression in human ocular barriers: implications for ocular drug disposition. Drug Metab Dispos. 2008;36(7):1300-1307.

49. Moreno-Navarrete JM, Ortega FJ, Rodriguez-Hermosa JI, et al. OCT1 expression in adipocytes could contribute to increased metformin action in obese subjects. Diabetes. 2011;60(1):168-176. doi: $10.2337 / \mathrm{db} 10-0805$
50. Lee N, Hebert MF, Prasad B, et al. Effect of gestational age on mRNA and protein expression of polyspecific organic cation transporters during pregnancy. Drug Metab Dispos. 2013;41(12):22252232.

51. Ito $\mathrm{N}$, Ito $\mathrm{K}$, Ikebuchi $\mathrm{Y}$, et al. Organic cation transporter/solute carrier family $22 \mathrm{a}$ is involved in drug transfer into milk in mice. $J$ Pharm Sci. 2014;103(10):3342-3348. doi:10.1002/jps.24138

52. Gilchrist SE, Alcorn J. Lactation stage-dependent expression of transporters in rat whole mammary gland and primary mammary epithelial organoids. Fundam Clin Pharmacol. 2010;24(2):205214.

53. Muller J, Lips KS, Metzner L, Neubert RH, Koepsell H, Brandsch M. Drug specificity and intestinal membrane localization of human organic cation transporters (OCT). Biochem Pharmacol. 2005;70 (12):1851-1860.

54. Han TK, Everett RS, Proctor WR, et al. Organic cation transporter 1 (OCT $1 / \mathrm{mOct} 1)$ is localized in the apical membrane of Caco-2 cell monolayers and enterocytes. Mol Pharmacol. 2013;84(2):182189.

55. Lips KS, Volk C, Schmitt BM, et al. Polyspecificcation transporters mediate luminal release of acetylcholine from bronchial epithelium. Am J Respir Cell Mol Biol. 2005;33(1):79-88. doi:10.1165/rcmb. 2004-0363OC

56. Schaeffeler E, Hellerbrand C, Nies AT, et al. DNA methylation is associated with downregulation of the organic cation transporter OCT1 (SLC22A1) in human hepatocellular carcinoma. Genome Med. 2011;3(12):82. doi:10.1186/gm298

57. More SS, Li S, Yee SW, et al. Organic cation transporters modulate the uptake and cytotoxicity of picoplatin, a third-generation platinum analogue. Mol Cancer Ther. 2010;9(4):1058-1069. doi:10.1158/1535-7163.MCT-09-1084

58. Hilgendorf C, Ahlin G, Seithel A, Artursson P, Ungell AL, Karlsson J. Expression of thirty-six drug transporter genes in human intestine, liver, kidney, and organotypic cell lines. Drug Metab Dispos. 2007;35(8):1333-1340.

59. Gupta S, Wulf G, Henjakovic M, Koepsell H, Burckhardt G, Hagos Y. Human organic cation transporter 1 is expressed in lymphoma cells and increases susceptibility to irinotecan and paclitaxel. $J$ Pharmacol ExpTher. 2012;341(1):16-23.

60. Namisaki T, Schaeffeler E, Fukui H, et al. Differential expression of drug uptake and efflux transporters in Japanese patients with hepatocellular carcinoma. Drug Metab Dispos. 2014;42(12):20332040.

61. Martinez-Becerra P, Vaquero J, Romero MR, et al. No correlation between the expression of FXR and genes involved in multidrug resistance phenotype of primary liver tumors. Mol Pharm. 2012;9 (6):1693-1704. doi:10.1021/mp300028a

62. Heise M, Lautem A, Knapstein J, et al. Downregulation of organic cation transporters OCT1 (SLC22A1) and OCT3 (SLC22A3) in human hepatocellular carcinoma and their prognostic significance. BMC Cancer. 2012;12:109. doi:10.1186/1471-2407-12-109

63. Saborowski M, Kullak-Ublick GA, Eloranta JJ. The human organic cation transporter-1 gene is transactivated by hepatocyte nuclear factor-4alpha. J Pharmacol Exp Ther. 2006;317(2):778-785.

64. Tirona RG, Lee W, Leake BF, et al. The orphan nuclear receptor HNF4alpha determines PXR- and CAR-mediated xenobiotic induction of CYP3A4. Nat Med. 2003;9(2):220-224. doi:10.1038/nm815

65. Stoffel M, Duncan SA. The maturity-onset diabetes of the young (MODY1) transcription factor HNF4alpha regulates expression of genes required for glucose transport and metabolism. Proc Natl Acad Sci USA. 1997;94(24):13209-13214. doi:10.1073/pnas.94.24. 13209

66. Kamiya A, Inoue Y, Gonzalez FJ. Role of the hepatocyte nuclear factor 4alpha in control of the pregnane $\mathrm{X}$ receptor during fetal liver development. Hepatology. 2003;37(6):1375-1384. doi:10.1053/jhep.2003.50212 
67. Jixuan L, Gang N, Stephen AD. Mammalian hepatocyte differentiation requires the transcription factor HNF-4 $\alpha$. Genes Dev. 2000;14(4):464-474

68. Inoue Y, Hayhurst GP, Inoue J, Mori M, Gonzalez FJ. Defective ureagenesis in mice carrying a liver-specific disruption of hepatocyte nuclear factor 4alpha (HNF4alpha). HNF4alpha regulates ornithine transcarbamylase in vivo. J Biol Chem. 2002;277 (28):25257-25265. doi:10.1074/jbc.M203126200

69. Hayhurst GP, Lee YH, Lambert G, Ward JM, Gonzalez FJ. Hepatocyte nuclear factor 4alpha (nuclear receptor 2A1) is essential for maintenance of hepatic gene expression and lipid homeostasis. Mol Cell Biol. 2001;21(4):1393-1403. doi:10.1128/ MCB.21.4.1393-1403.2001

70. Duncan SA, Nagy A, Chan W. Murine gastrulation requires HNF-4 regulated gene expression in the visceral endoderm: tetraploid rescue of Hnf-4(-/-) embryos. Development. 1997;124(2):279-287.

71. Watt AJ, Garrison WD, Duncan SA. HNF4: a central regulator of hepatocyte differentiation and function. Hepatology. 2003;37 (6):1249-1253. doi:10.1053/jhep.2003.50273

72. Kajiwara M, Terada T, Asaka J, et al. Regulation of basal core promoter activity of human organic cation transporter 1 (OCT1/ SLC22A1). Am J Physiol Gastrointest Liver Physiol. 2008;295(6): G1211-G1216. doi:10.1152/ajpgi.90360.2008

73. Hyrsova L, Smutny T, Carazo A, et al. The pregnane X receptor down-regulates organic cation transporter 1 (SLC22A1) in human hepatocytes by competing for ("squelching") SRC-1 coactivator. $\mathrm{Br} \quad J$ Pharmacol. 2016;173(10):1703-1715. doi:10.1111/bph.13472

74. Min G, Kim H, Bae Y, Petz L, Kemper JK. Inhibitory cross-talk between estrogen receptor (ER) and constitutively activated androstane receptor (CAR). CAR inhibits ER-mediated signaling pathway by squelching p160 coactivators. $J$ Biol Chem. 2002;277 (37):34626-34633. doi:10.1074/jbc.M205239200

75. Cahill MA, Ernst WH, Janknecht R, Nordheim A. Regulatory squelching. FEBS Lett. 1994;344(2-3):105-108. doi:10.1016/ 0014-5793(94)00320-3

76. Rulcova A, Krausova L, Smutny T, et al. Glucocorticoid receptor regulates organic cation transporter 1 (OCT1, SLC22A1) expression via HNF $4 \alpha$ upregulation in primary human hepatocytes. Pharmacol Rep. 2013;65(5):1322-1335.

77. Kamiyama Y, Matsubara T, Yoshinari K, Nagata K, Kamimura H, Yamazoe Y. Role of human hepatocyte nuclear factor 4alpha in the expression of drug-metabolizing enzymes and transporters in human hepatocytes assessed by use of small interfering RNA. Drug Metab Pharmacokinet. 2007;22(4):287-298. doi:10.2133/ dmpk.22.287

78. Castell JV, Jover R, Martinez-Jimenez CP, Gomez-Lechon MJ. Hepatocyte cell lines: their use, scope and limitations in drug metabolism studies. Expert Opin Drug Metab Toxicol. 2006;2 (2):183-212. doi:10.1517/17425255.2.2.183

79. Ciarimboli G, Koepsell H, Iordanova M, et al. Individual PKCphosphorylation sites in organic cation transporter 1 determine substrate selectivity and transport regulation. J Am Soc Nephrol. 2005;16(6):1562-1570.

80. Hui L, Zatloukal K, Scheuch H, Stepniak E, Wagner EF. Proliferation of human HCC cells and chemically induced mouse liver cancers requires JNK1-dependent $\mathrm{p} 21$ downregulation. $J$ Clin Invest. 2008;118(12):3943-3953. doi:10.1172/JCI37156

81. Chang Q, Chen J, Beezhold KJ, Castranova V, Shi X, Chen F. JNK1 activation predicts the prognostic outcome of the human hepatocellular carcinoma. Mol Cancer. 2009;8:64.

82. Lautem A, Heise M, Grasel A, et al. Downregulation of organic cation transporter 1 (SLC22A1) is associated with tumor progression and reduced patient survival in human cholangiocellular carcinoma. Int $J$ Oncol. 2013;42(4):1297-1304. doi:10.3892/ ijo.2013.1840
83. Lambert MP, Paliwal A, Vaissiere T, et al. Aberrant DNA methylation distinguishes hepatocellular carcinoma associated with HBV and HCV infection and alcohol intake. J Hepatol. 2011;54(4):705715. doi:10.1016/j.jhep.2010.07.027

84. Asghar U, Meyer T. Are there opportunities for chemotherapy in the treatment of hepatocellular cancer? J Hepatol. 2012;56(3):686695. doi:10.1016/j.jhep.2011.07.031

85. Llovet JM, Bruix J. Systematic review of randomized trials for unresectable hepatocellular carcinoma: chemoembolization improves survival. Hepatology. 2003;37(2):429-442. doi:10.1053/ jhep.2003.50047

86. Bengala C, Bertolini F, Malavasi N, et al. Sorafenib in patients with advanced biliary tract carcinoma: a phase II trial. Br J Cancer. 2010;102(1):68-72. doi:10.1038/sj.bjc.6605458

87. Geier A, Macias RI, Bettinger D, et al. The lack of the organic cation transporter OCT1 at the plasma membrane of tumor cells precludes a positive response to sorafenib in patients with hepatocellular carcinoma. Oncotarget. 2017;8(9):15846-15857. doi:10.18632/oncotarget.15029

88. Strumberg D, Clark JW, Awada A, et al. Safety, pharmacokinetics, and preliminary antitumor activity of sorafenib: a review of four phase I trials in patients with advanced refractory solid tumors. Oncologist. 2007;12(4):426-437. doi:10.1634/theoncologist.12-4-426

89. Abou-Alfa GK, Schwartz L, Ricci S, et al. Phase II study of sorafenib in patients with advanced hepatocellular carcinoma. J Clin Oncol. 2006;24(26):4293-4300. doi:10.1200/JCO.2005.01.3441

90. Grimm D, Lieb J, Weyer V, et al. Organic Cation Transporter 1 (OCT1) mRNA expression in hepatocellular carcinoma as a biomarker for sorafenib treatment. BMC Cancer. 2016;16:94. doi:10.1186/s12885-016-2150-3

91. Zhang S, Lovejoy KS, Shima JE, et al. Organic cation transporters are determinants of oxaliplatin cytotoxicity. Cancer Res. 2006;66 (17):8847-8857. doi:10.1158/0008-5472.CAN-06-0769

92. Minematsu T, Giacomini KM. Interactions of tyrosine kinase inhibitors with organic cation transporters and multidrug and toxic compound extrusion proteins. Mol Cancer Ther. 2011;10(3):531539. doi:10.1158/1535-7163.MCT-10-0731

93. Zach O, Krieger O, Foedermayr M, Zellhofer B, Lutz D. OCT1 (SLC22A1) R61C polymorphism and response to imatinib treatment in chronic myeloid leukemia patients. Leuk Lymphoma. 2008;49(11):2222-2223. doi:10.1080/10428190802322893

94. Al-Abdulla R, Lozano E, Macias RIR, et al. Epigenetic events involved in organic cation transporter 1-dependent impaired response of hepatocellular carcinoma to sorafenib. $\mathrm{Br} J$ Pharmacol. 2019;176(6):787-800. doi:10.1111/bph.14563

95. Lozano E, Macias RIR, Monte MJ, et al. Causes of hOCT1-dependent cholangiocarcinomaresistance to sorafenib and sensitization by tumor-selective gene therapy. Hepatology. 2019. Epub ahead of print. doi:10.1002/hep.30656

96. Funk C. The role of hepatic transporters in drug elimination. Expert Opin Drug Metab Toxicol. 2008;4(4):363-379. doi:10.1517/1742 5255.4.4.363

97. Hayer-Zillgen M, Brüss M, Bönisch H. Expression and pharmacological profile of the human organic cation transporters hOCT1, hOCT2 and hOCT3. Br $J$ Pharmacol. 2002;136(6):829-836. doi:10.1038/sj.bjp.0704785

98. Gründemann D, Liebich G, Kiefer N, Köster S, Schömig E. Selective substrates for non-neuronal monoamine transporters. Mol Pharmacol. 1999;56(1):1-10.

99. Boxberger KH, Hagenbuch B, Lampe JN. Common drugs inhibit human organic cation transporter 1 (OCT1)-mediated neurotransmitter uptake. Drug Metab Dispos. 2014;42(6):990-995.

100. Chen L, Shu Y, Liang X, et al. OCT1 is a high-capacity thiamine transporter that regulates hepatic steatosis and is a target of metformin. Proc Nat Acad Sci USA. 2014;111(27):9983-9988. doi:10.1073/pnas.1314939111 
101. Koepsell H. The SLC22 family with transporters of organic cations, anions and zwitterions. Mol Aspects Med. 2013;34(23):413-435. doi:10.1016/j.mam.2012.10.010

102. Yin J, Duan H, Shirasaka Y, Prasad B, Wang J. Atenolol renal secretion is mediated by human organic cation transporter 2 and multidrug and toxin extrusion proteins. Drug Metab Dispos. 2015;43(12):1872-1881.

103. Nies AT, Koepsell H, Damme K, Schwab M. Organic cation transporters (OCTs, MATEs), in vitro and in vivo evidence for the importance in drug therapy. Handb Exp Pharmacol. 2011;201:105-167.

104. Iwai M, Minematsu T, Li Q, Iwatsubo T, Usui T. Utility of P-glycoprotein and organic cation transporter 1 double-transfected LLC-PK1 cells for studying the interaction of YM155 monobromide, novel smallmolecule survivin suppressant, with P-glycoprotein. Drug Metab Dispos. 2011;39(12):2314-2320. doi:10.1124/dmd.111.040733
105. Saadatmand AR, Tadjerpisheh S, Brockmöller J, Tzvetkov MV. The prototypic pharmacogenetic drug debrisoquine is a substrate of the genetically polymorphic organic cation transporter OCT1. Biochem Pharmacol. 2012;83(10):1427-1434.

106. Ishiguro N, Shimizu H, Kishimoto W, Ebner $\mathrm{T}$, Schaefer O. Evaluation and prediction of potential drug-drug interactions of linagliptin using in vitro cell culture methods. Drug Metab Dispos. 2013;41(1):149-158.

107. Yonezawa A, Masuda S, Yokoo S, Katsura T, Inui K. Cisplatin and oxaliplatin, but not carboplatin and nedaplatin, are substrates for human organic cation transporters (SLC22A1-3 and multidrug and toxin extrusion family). $J$ Pharmacol Exp Ther. 2006;319 (2):879-886.

\section{Publish your work in this journal}

OncoTargets and Therapy is an international, peer-reviewed, open access journal focusing on the pathological basis of all cancers, potential targets for therapy and treatment protocols employed to improve the management of cancer patients. The journal also focuses on the impact of management programs and new therapeutic agents and protocols on patient perspectives such as quality of life, adherence and satisfaction. The manuscript management system is completely online and includes a very quick and fair peer-review system, which is all easy to use. Visit http://www.dovepress.com/ testimonials.php to read real quotes from published authors. 